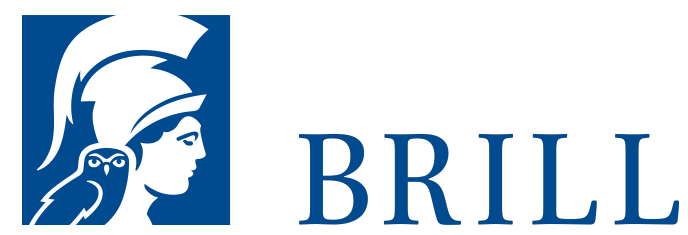

\title{
Bildung und die Grenzen der Erfahrung
}

Randgänge der Bildungsphilosophie

Author: Christiane Thompson

Unter Rückgriff auf klassische wie gegenwärtige

Erfahrungskonzeptionen nimmt die vorliegende Studie die

Provokation einer unmöglichen Identität mit sich selbst in das

Bildungsdenken auf und benennt Anschlüsse für eine kulturwissenschaftliche Bildungsforschung. Gegen die heute dominante Steigerungs- und Vermessungslogik von Bildung lässt sich fragen, inwiefern 'Bildung' das Subjekt mit einem unproblematischen Selbstbezug ausstattet. Die klassische Bildungstheorie verweist an dieser Stelle nicht auf kumulative Erfahrungsverläufe, sondern auf Vorgänge, die das Subjekt an die Grenzen seiner Erfahrung und Erfahrungsfähigkeit führen. Nach Adorno machen diese Grenzen eine Fremdheit von Selbst und Welt greifbar, die nicht im Sinne eines Kom-petenzerwerbs überwunden werden können. Foucault spricht gar von einer Auflösung des Subjekts in der Grenzerfahrung. Dies legt nahe, die Kategorie der Bildung als Sensor für 'Differenz' in der Analyse von Subjektivierungsprozessen einzusetzen.

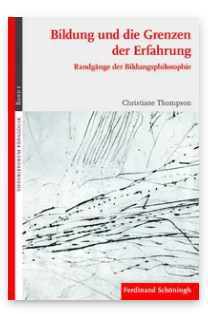

Pages: 243

Seiten

Language:

German

Subjects:

General,

Education

Publisher: Brill |

Schöningh

Series:

Theorieforum

Pädagogik,

Volume: 1

E-Book (PDF)

Released online:

og Dec 2019

ISBN: 978-3-

657-76721-2

List price

Paperback

Publication date: 16 Sep 2009

ISBN: 978-35०6-76721-9

List price 
For more information see brill.com

Order information: Order online at brill.com +44330 333 0049 | customerservices@brill.com Submission information: brill.com/authors

Titles published by Brill | Fink, Brill | mentis or Brill | Schöningh: +49(o)715413279216| brill@brocom.de 